\title{
Study on the Characteristics of Knights in Chinese Classical Literature
}

\author{
Gaixia Wei ${ }^{1}$ \\ ${ }^{1}$ Zhengzhou Institute of Applied Technology, Xinzheng, Henan, 451150
}

KEYWORDS: Knight; Characteristics; Chinese Classical Literature

\begin{abstract}
Human Chong Knights consciousness can be traced back to ancient times, this is decided by the harsh natural conditions and living environment as well as the law of survival. The first sense of Knight in Chinese literature and history can be pushed to the original myths and legends of magic has the characteristic of archetype. Bent along down to the Spring and Autumn era appeared "Shi" class, and package them civil and military, set in a Confucian Knight, in fact, part of the exercise of the duties and responsibilities of Chivalry. Then later, before Central derive professional scribes, "which is called disabilities', and with the ancients; being to the tongue, and the ancients different, so is the degeneration of the samurai and the scribes.
\end{abstract}

\section{Introduction}

Ancient China admiring Knights consciousness has long history. From the Warring States to Ming and Qing thousands of years, from generation to generation Jie knight dash. Knight as a special social groups, not only to live in various historical periods of ancient China, but deep into all levels of society: "From ancient Yi Yin, Confucius, then, for the self-Ying, down to the cave, and the woman woman shoots bang his ilk, Ho-generation Man, Man Ho is not surprising. " Reason for the knight of worship, our predecessors have also had to address. As early as the Han Dynasty, Sima Qian in the "Historical Ranger Biography" on that social reasons knight of worship: "priorities, when the person also." And its inherent cultural and psychological factors, then, as Mr. Renew said: " the general public, at the time suffered extreme oppression of tyranny, full stomach filling with anger and injustice, but due to lack of power, cannot resist, so naive in their psychological, is looking forward to hanging a class of `Superman 'in knight out to without a trace, go without a trace of snow for their injustice, in addition to rape.

\section{Knight Characteristics of Evolution and Mutation}

With respect to the housing of the temple, commoner Man due to "save lives in Ecuador," and "stick in the text when the world of weeks", cannot help but fear often kill the body, it must be hidden lakes. Zhu, Guo Jie Ju is the early Han Dynasty heroes, they save lives, Tibetan death satisfied dead, dispute resolution, "to borrow the body cross revenge", often urgency of the poor, "Zhen people do not age support, starting with the humble beginning ", the weak efforts to save the poor, is Zhu, Guo Jie has a very high prestige in the political arena. Zhu "from off to the east, everyone is willing to pay Yan extension of the neck." Guo Guan Jie-ren, "Guan Yin Hao in knowing and not knowing, heard and fight intercourse solution", "A World Without yin and unworthy, knowing and not knowing, all admire his voice, by key words Knight proud name." Zhu, Guo Jie's main living space is relative to the temple of the dead, they look high reputation in the political arena long, pre-loaded, no one can. At that time the young people they admire, they have violated the people, "Noir is also revenge" and "not to know it." There is a Confucian scholar, said 
Guo Jie "special public law to commit rape, what Yin", it was amputated tongue, give their lives; Guo Jie is the official migration to Maoling, "Yang Ji master plot for the county rafters, for migration solution "Solutions will be Guo nephew killed. Early Han rangers sloppily, rampant rivers and lakes, "Red daylight murder, the well-known Jingzhao dare catch." They mostly just civil injustice, rivers and lakes right and wrong, and not participate in the strife of political forces, and living in the temple on top the dignitaries who have hidden potential rival.

To the gallant in Tang Legends is inextricably linked with the official. The red line is Luzhou Jiedushi Xue pole Fuchu Tsing Yi slave girl; as Nie Nie Feng Wei Bo Jiedushi the hands of generals daughter; Old Yaya is Yamen Xiaoli. Compared alienated temple Ranger Han Dynasty, Tang Dynasty gallant have been more or less involved in the political and military strife: red burglar Tiancheng Si Weibo Jiedushi bedside gold box; Nie Chen Xu repeatedly retreat Jiedushi Liu Changyi assassin; insect $\mathrm{L}$ beard off but there is a king FIG ambition. These gallant although not as famous officials will re-use, but most of them end non-temples of the people, they come from the political arena, and ultimately to be attributed to the political arena. If the Ranger is rampant in the top corners of the country, with representatives of the orthodox temple implicitly proposition; gallant is torn between the lakes and temples, and eventually return to the political arena, then chivalrous detective novels official Knight is abandoning the political arena, board according to the temple. "Chivalric Heroes" in the Southern Man Chan Chao has been called the four products knife guard, Lu Fang, Xu Qing, Jiang Ping and others are also the Captain of six products. "Green Peony" has been called An Guogong in Baozi An, Cao has been called flower set national companies, and the rest of the people are not taking part, it is general. "Seven Swords thirteen Man" was the total of each town are righteous, lieutenant, admirals and other raised him. These Jianghuhaoke has bid farewell to its former full of swords, but the vivid arena of life, beginning with brown purple clothes, Diange become minister of state. After the temple by the knight who Sakamoto, getting rid of their behavior will not only have a chivalric record straight in nature and will be a representative of the government's activities. Once isolated knight and the rivers and lakes, separated from the personal heroism, then less of $\mathrm{Xu}$ abstract hero on rivers and lakes, and in the official catch more than a poor handling of $\mathrm{Li} \mathrm{Zu}$.

Sima Qian in "Ranger Tales" for the knight gave a definition: "this Ranger, although against the law in its line of justice, then it stands by its word, its action must have promise will be honest, do not love their hindquarters, go to the disabilities trapped, survival and death Now that men, which can not boast, cutting its German shame "Knight pointed out that the definition of" stands by its word, line must be fruit, "' has promise will honesty "honest and trustworthy character; having "the scholar went trapped", "do not love their hindquarters," the spirit of self-sacrifice: a humble nature, "it cannot boast, shame cutting its virtue". In other words, with these three features it is the Man. Man acting principle is responsive, there must be the end, but not everywhere can be significant, frequently boast Germany. Zhu "Tibetan living Oshkosh to a few hundred, the rest mediocre words can not win," but "the end does not cutting their energy, their desire virtue, such as taste Shi, lest see it." Zhu saved the famous quarter cloth, "cloth and noble, but not for life also." Guo Jie restricted to mediate disputes, not only did not claim credit vows, while the monthly credit _ will make with others. Zhu "Xu home without money, clothing endless mining, food taste is not heavy, but the horse ride cow." When the drama Meng dead, "Xu no home ten gold wealth."

Chinese Novels gallant often played when bits are not prominent, not look, after Knight Bank floated there anymore, a "thing Fuyi go explore and hiding the name of" grace and air-bone. Old Yaya "village villa living" ("Warriors Biography"), Lan Ling elderly "buried hetero-shaped track" ("Lanling elderly"), as a red line "Yi slave girl." Once the line Knight success, Nie "Since seeking 
access to the human landscape" ("Nie"), red line "was dead in its" take Ungrateful Zeishou swordsman is "do not know that the" ("Yi Knight"). In the Tang Legend knight mostly ignited dust, normally does not reveal the landscape, only occasionally a danger now towering, in turn hidden in the vast world of mortals. For them, the line means Knight martial art just necessary, rather than stepping stone, Monkey this. When commoner to go still commoner, red end generation captive "commoner Man" character.

As Chen Pingyuan said: "From the Tang Knight gallant novels, detective novels of chivalry to the Qing Dynasty Knight, the biggest change is the ability to fight with the world of thoughts and feelings of secularization." battle of wits and put aside or feijian or genuine real knife fight aside, here referred to "the thoughts and feelings of secularization" specific performance, is the official Knights are no longer free to pursue the political arena

Scholars no smell of, but rather believe in "learning martial arts written, selling to the imperial family," I hope knife shot to Bo a seal wife Yam son. They no longer have the Han and Tang knight "But so strong Krupp off, why a brother to" weather vane, but their pursuit of fame and fortune, the dream of "cut named Wang Xiangui Palace, Monkey plays in the 1st brother." "Shi Gong" in Huangtian Ba unmistakably that "small is classic, only to map name motivated." He Tianbao Greenwood was abandoned for a "long after, earned a fame, vigor and vitality." "Green Peony" in Baozi An also said, "Why do not I go and so congenial, escort troops to the capital, the size of the office to get hold of, but also Mont Royal seal gifts." And when you surrender all knight of clean government, also tend to fame as bait. "Shi Gong" in Shi Shi-Lun Chang said: "This righteous go hand in hand if you are willing, Ru few credit Shimou will certainly Qizou reuse master today, from hero to worry about body Ronggui significant." The late Qing Dynasty scholar criticized popular when Chivalrous Detective Stories: "Today robber tomorrow Shoujue, the rebellion of insubordination by the line, take a shot for the position of power", pointed out sharply critical of such novels in the "power position" word. Surface Shang Knight are keen to follow in conformity with imperial and clean government, in fact, it is pursued fame official post.

\section{Mutation Reasons of Knights Feature}

Knight existence and development of national institutions is a prerequisite for incomplete and the law is not perfect, but with the gradual integration of the feudal society, the development of "Law \& Order" gradual improvement, knight living space getting smaller and smaller. Greenwood Fa outside of the political arena is gradually being integrated into the normal legal society. Former knight who can breathe freely, Happy paradise gradually ceased to exist. And that "with the development of sound feudal state, various institutions and organizations functioning on track ... ... a variety of social ills can only be prescribed within the digestion system, if the individual to play the role of savior, will be subject to the laws and rituals from both censure and even be prosecuted. Ranger's presence is almost impossible. " (8) knight who record straight, getting rid of the original by the community for their support and praise, sometimes occasionally official connivance, but "with the development of the feudal state of sound", then his hands knight sword for good, will be subject to many blame. Is this "centrifugal forces" or be destroyed, or were among the people satisfied state apparatus.

Especially in the Qing Dynasty, "Manchu Guan, China gradually being crushed, even have` Knightqi 'who did not dare to steal renewed heart, dare not criticize the traitor, not directly to the effectiveness of the emperor, then followed by a good officer or imperial envoy, give him a bodyguard, for he caught stealing, a "Shi Gong" also made it very clear. There are "Peng Detective," "five Seven Chivalrous justice" and his ilk, has no end. "L While the knight who 
"servility also followed to add a little", but after all, in the case of rivers and lakes Greenwood difficult to re-long shelter, but also opened up another living space, "safety has increased." "Shi Gong after the transfer," ninety-back, knight meter-wide application of persuasion may lead to passage fairly representative: "I want you between childhood frivolous rob for a living, mixed half-empty, older is not small , and shall be deemed to think of the idea of retirement, in order to secure the jobs of close results, ... you and I are old, Fa also tight, and this time, cannot think of result, it is difficult for the man I . "Wong Tin-bar is once they see through the" Greenwood no good ", he defected to the early official. Even Chan Chao felt that "this official once the fetters of anti-sense mind cannot be fun," but we can only do it honestly, "Royal cat." Imagine if more as the Han and Tang knight against the rulers commit Fajin, private line righteousness, Bo private name, then the result can be imagined.

\section{Conclusion}

In the world culture history, rulers and against Tan Bao respected uprising punishing evil behavior Robin, thereby internalized into a universal respect Pirates Mu Knight folk psychology and literary motif, the West all ethnic groups have in common. Modern and Contemporary Literature Knight martial art and further fictionalized, both the spirit of independent special line, but also superb martial arts and safeguard fairness and justice of morality, but also has human beauty in the martial arts and detective, romance and even supernatural integration, human Once upon freedom Chipin, indicating their nostalgia and the Chivalrous spirit Pursues Complex. Man can say that the spirit of past and present performance of each other, have not been severed use knight literature embodied the aesthetic value of the standard over charisma and national psychology cohesion, abandon negative factors behind the times, but our attitudes.

\section{Reference:}

[1] Zhang Jingru. Anthology (Volume 2) [M]. Shenzhen: Haitian Press, 2006: 448.

[2] Yu Xiaohong. Research and Buddhism in Tang vernacular novels [M]. Beijing: People's Publishing House, 2006.

[3] Yang Bojun. Annotation of Mencius [M]. Beijing: Zhonghua Book Company, 1960: 251.

[4] Yi Zheer. Reading activities: aesthetic response theory [M]. Beijing: China Renmin University Press, 1988.

[5] Encyclopedia of China Education [M]. Beijing: Encyclopedia of China Publishing House, 1985: 207. 